\title{
Validation of Commercial ELISA kit for Non-Invasive Measurement of Cortisol Concentrations and the Evaluation of the Sampling Time of Blood and Fecal Sample in Aceh Cattle
}

\author{
Gholib Gholib ${ }^{1}$, Sri Wahyuni ${ }^{2}$, Ahmad Wahyudi ${ }^{3}$, Khoiriyah S. Silalahi ${ }^{3}$, Muslim Akmal $^{4}$, Mustafa Sabri $^{2}$, and Taufiq \\ P. Nugraha ${ }^{5 *}$ \\ ${ }^{1}$ Physiology Laboratory, Faculty of Veterinary Medicine, Universitas Syiah Kuala, Banda Aceh, Aceh, 23111, Indonesia \\ ${ }^{2}$ Anatomy Laboratory, Faculty of Veterinary Medicine, Universitas Syiah Kuala, Banda Aceh, Aceh, 23111, Indonesia \\ ${ }^{3}$ Study Program of Veterinary Education, Faculty of Veterinary Medicine, Universitas Syiah Kuala, Banda Aceh, 23111 Indonesia \\ ${ }^{4}$ Histology Laboratory, Faculty of Veterinary Medicine, Universitas Syiah Kuala, Banda Aceh, Aceh, 23111, Indonesia \\ ${ }^{5}$ Laboratory of Reproduction Division of Zoology, Research Center for Biology, Indonesian Institute of Sciences (LIPI), Bogor, \\ Indonesia
}

\begin{abstract}
Some parameters should be evaluated before the analysis of cortisol hormone using enzyme-linked immunosorbent assay ( ELISA). The most important one is to test the validity of the ELISA kit itself since most of the commercially available ELISA kit is not designed for animal use. The time of sample collection is also another important parameter needed to be evaluated due to a known diurnal variation of cortisol concentrations. This study aims to validate a commercial ELISA kit and evaluate the sampling time on the diurnal variations of cortisol concentration in blood and feces of Aceh cattle. Blood and fecal samples were collected in the morning and afternoon from 8 Aceh cows aged 2-3 years. A commercial ELISA Kit (Cat. No. EIA-K003-H5, Arbor Assays ${ }^{\circledR}$ ) was validated using analytical (parallelism, accuracy, and precision/\% $\mathrm{CV}$ of intra- and inter-assay) and biological validations (by analyzing sample pre- and post-transportation). The results of a parallelism test showed the diluted sample curve from the fecal extract was not significantly different (parallel) to the standard curve of EIA-K003-H5 kits ( $p>0.05$ ), the accuracy of the assay: 99,76 \pm $3.77 \%$, and the $\% \mathrm{CV}$ of intra-and inter-assay less than $10 \%$. The results from the biological validation test showed that the concentrations of fecal cortisol post-transportation were significantly higher compared to the pre-transportation $(\mathrm{P}<0.05)$. Plasma cortisol concentrations collected in the morning were significantly higher $(79.34 \%)$ compared to afternoon samples $(\mathrm{P}<0.05)$. However, cortisol concentrations in feces collected in the morning and afternoon did not show a significant difference $(\mathrm{P}>0.05)$. In conclusion, ELISA Kit (EIA-K003H5, Arbor Assays ${ }^{\circledR}$ ) is a reliable assay for measuring cortisol in the feces of Aceh cows. Plasma cortisol concentrations in Aceh cows show a diurnal variation which is higher in the morning than afternoon, but the concentration of cortisol in the fecal sample did not.
\end{abstract}

Keywords: Aceh cattle, non-invasive, validation, sample collection time, ELISA, diurnal variation.

\section{Introduction}

Global warming has increased the surface temperatures around $0.7^{\circ} \mathrm{C}$ since the beginning of the $20^{\text {th }}$ century and is expected to rise to 1.8 to $4^{\circ} \mathrm{C}$ by 2100 [1]. This has a wide impact on the agriculture and livestock sectors particularly due to the effect of heat stress. Heat stress is widely known to affect domestic animals' performance such as suppress the immune system and even causing reproductive health disorders [2]. The direct impact of heat stress on reproduction is the increased incidence of silent estrus, inhibition of hormone secretion, failure of fertilization, decreased conception rates and premature embryonic death [3-4].

Aceh cattle have been declared as native Indonesian beef cattle based on Minister of Agriculture Decree
Number 2907 / Kpts /OT.140/6/2011 2011. The productivity of Aceh cattle is still relatively low. One of the problems is caused by heat stress. To evaluate the levels of stress, it is mostly done through the cortisol measurements in blood samples using an enzyme-linked immunosorbent assay (ELISA) technique [5]. However, these invasive procedures can cause stressed to the animal itself due to the process of handling and restraint and can bias the results due to the stress that arises during sampling [6].

A recently non-invasive technique for monitoring hormone levels through fecal samples has become a preferred tool for field researchers [7-8]. However, there are some precautions in using commercially available ELISA kits for the measurement of fecal hormones. Firstly, most of these kits are intended for blood samples.

\footnotetext{
* Corresponding author: tragulus@gmail.com
} 
Second, there is a commercial ELISA kit developed for measuring hormones in feces or urine, but it is not specifically intended for animals especially cattle. Therefore, several factors must be considered before conducting hormone analysis, and it is called preanalytical factors. Pre-analytical factors include the time of sample collections [9], sample preservation and storage time [8], preparation and processing techniques [7], and validation of the ELISA kit used $[5,10]$.

The time of sample collection must be considered. This is due to the diurnal pattern of hormone secretion (i.e., cortisol) called the circadian rhythm. It may cause differences in cortisol secretion in the morning and afternoon. Pawluski et al. [11] reported that the highest plasma cortisol concentrations in horses are in the morning $(28.5 \pm 1.4 \mathrm{ng} / \mathrm{ml})$, while the lowest concentration was reached in the afternoon $(15.2 \pm 1.8 \mathrm{ng} / \mathrm{ml})$. A study In brown spider monkeys, morning concentrations of fecal samples are higher $(203 \pm 10 \mathrm{ng} / \mathrm{g}$ feces $)$ compared to the afternoon samples ( $83 \pm 13 \mathrm{ng} / \mathrm{g}$ feces) [12]. However, on some species such as gorillas (morning: $114.1 \pm 52.0 \mathrm{ng} / \mathrm{g}$ feces, afternoon: $121.5 \pm 67.9 \mathrm{ng} / \mathrm{g}$ feces) [13], and howler monkeys (morning: $287 \pm 80 \mathrm{ng} / \mathrm{g}$ feces, afternoon: $284 \pm 23 \mathrm{ng} / \mathrm{g}$ feces) [12], there are no differences between the concentration of fecal cortisol in the morning and the afternoon. Therefore, it is necessary to evaluate the sampling time in each species.

Measurement of cortisol hormone concentration using ELISA methods requires a cortisol ELISA kit. It can use a commercially available ELISA kit or a custom home assay kit that made specifically for the intended purpose. When a commercial ELISA kit is preferred, it is very important to conduct a validation test on the kit. This is especially when the ELISA kit used is not specifically designed for the intended animal or the type of sample used (e.g., fecal samples). Validation tests include analytical validation and biological/physiological validation. Both tests aim to validate the reliability of the ELISA kit used in measuring the concentration of the intended hormone [5].

The present study was conducted to 1) examine the validity of commercially available cortisol ELISA kits (Cat. No.EIA-K003-H5, Arbor Assays $®$ ) to measure cortisol hormone in fecal samples of Aceh cattle, and 2) evaluate the effect of sampling time on diurnal variation of cortisol concentrations in blood and fecal samples of Aceh cattle.

\section{Materials and Methods}

\subsection{Study animals}

Blood and fecal samples were collected from eight female Aceh cattle (cow), aged 2-3 years, from a teaching farm (UPT hewan coba), Faculty of Veterinary Medicine, Universitas Syiah Kuala, Banda Aceh. These cows were housed together in stables using a colony housing system. Cattle housing was equipped with feed and water troughs.

\subsection{Collection and preparation of blood samples}

Blood samples were collected in the morning (06.00 to 08.00) and the afternoon (12.00 to14.00) from the jugular vein. A $3 \mathrm{ml}$ blood samples were then placed into a tube containing Ethylenediaminetetraacetic acid (EDTA) to prevent blood clots. Blood samples were then centrifuged at $1200 \mathrm{xg}$ for 10 minutes at $4^{\circ} \mathrm{C}$. The plasma obtained was stored in a freezer of $-20{ }^{\circ} \mathrm{C}$ until hormone measurements.

\subsection{Collection, preparation, and extraction of fecal samples}

Fecal samples were collected in the morning at 06.00 to08.00 and afternoon at 12.00 to13.00. Approximately, $10 \mathrm{~g}$ of fecal samples are collected immediately after defecation and dried using an oven [7]. Fecal samples were placed in the oven at $50^{\circ} \mathrm{C}$ for 3 days until the fecal sample was dried evenly. The dried feces was then pulverized to get the fecal powder. $\sim 0.5 \mathrm{~g}$ fecal powder was put into a tube containing $3 \mathrm{ml}$ of $80 \%$ methanol. The mixture was then extracted using a multitube vortexer for 10 minutes. Afterward, the mixture was centrifugated for 10 minutes at $3000 \mathrm{rpm}$ and the supernatant (fecal extract) was then decanted into 2 $\mathrm{ml}$ microtube. $0.5 \mathrm{ml}$ of fecal extract is aliquoted in a tube that is covered with the perforated parafilm and then dried in an oven at $37^{\circ} \mathrm{C}$ for 2 days until the solvent disappears Afterward, $0.5 \mathrm{ml}$ of assay buffer is added into the tube and then vortexed until homogeneous and stored at $-20{ }^{\circ} \mathrm{C}$ in freezer until hormone analysis.

\subsection{ELISA kit validation}

Validation of a commercial cortisol ELISA Kit (EIAK003-H5, Arbor Assays ${ }^{\circledR}$ ) is conducted through analytical and biological validation as described by Gholib et al. [5]. . The analytical validation consists of a parallelism test, accuracy, and precision (\% coefficient variation (CV) of intra- and inter-assay), while the sensitivity was reported as written in the ELISA Kit manual (product protocol). Biological validation was performed by comparing cortisol concentrations before and after transport. Fecal samples were collected from three cows before and after being transported.

\subsection{Cortisol measurements}

The measurement of cortisol concentrations in plasma samples was conducted using a commercial cortisol ELISA kit produced by DRG Instrument $\mathrm{GmBH}$, Germany ( Cat. No. EIA-1887). This assay has been validated for Aceh cattle [5]. A total of $20 \mu \mathrm{L}$ of solution standards and $20 \mu \mathrm{L}$ samples were filled into microplate wells. Furthermore, $200 \mu \mathrm{L}$ of the enzyme-conjugate was added to each well except for the blank well, covered with cling film and homogenized for 10 seconds by slow shaking. The microplate was then incubated at room temperature for 60 minutes and then washed four times 
using $300 \mu \mathrm{L}$ of washing solution on each well. Subsequently, a $200 \mu \mathrm{L}$ substrate solution (TMB) was added to each well and covered with the cling film and then re-incubated for 20 minutes at room temperature. A total of $100 \mu \mathrm{L}$ stop solution $\left(0.5 \mathrm{M} \mathrm{H}_{2} \mathrm{SO}_{4}\right)$ was added to each well to stop the enzymatic reaction. The absorbance was determined by using an ELISA reader $\left(\mathrm{xMark}^{\mathrm{TM}}\right.$ Microplate Absorbance Spectrophotometer, Bio-Rad Laboratories Inc.) at $450 \mathrm{~nm}$. The concentration of cortisol was then calculated using the Microplate Manager ® 6 Software (Bio-Rad Laboratories Inc.).

Measurement of cortisol concentration in fecal samples was conducted using a commercial cortisol ELISA kit produced by Arbor Assays ${ }^{\circledR}$ (Cat. No. EIA$\mathrm{K} 003-\mathrm{H} 5) 50 \mu \mathrm{L}$ of standard and samples were filled into the microplate well. Moreover, $75 \mu \mathrm{L}$ of assay buffer was filled into the non-specific binding (NSB) wells and 50 $\mu \mathrm{L}$ of assay buffer into the maximum binding (B0 or Zero standard) well. Afterward, $25 \mu \mathrm{L}$ of the DetectX® cortisol conjugate was added to each well using a repeater pipet. $25 \mu \mathrm{L}$ of the DetectX® cortisol antibody was then added to each well, except the NSB wells. The microplate was then covered with the plate sealer, homogenized for 10 seconds and then incubated at room temperature for 1 hour. After that, the microplate was washed with $300 \mu \mathrm{L}$ of washing solution four times. Afterward, $100 \mu \mathrm{L}$ of TMB substrate solution was added to each well and cover with the sealer plate and then re-incubate for 30 minutes at room temperature. Finally, $50 \mu \mathrm{L}$ stop solution $(0.5 \mathrm{M}$ $\mathrm{H} 2 \mathrm{SO} 4$ ) was added to each well to stop the enzymatic reaction. The absorbance was determined by using an ELISA reader $\left(\right.$ xMark $^{\mathrm{TM}}$ Microplate Absorbance Spectrophotometer, Bio-Rad Laboratories Inc.) at 450 nm. The concentration of cortisol was then calculated using the Microplate Manager ® 6 Software (Bio-Rad Laboratories Inc.).

\subsection{Data analysis}

The parallelism test data were analyzed using the test of equality of slope between the sample curve and the standard curve [14]. The precision data is calculated based on the \% CV of intra- and inter-assay of the standard control with the formula [(standard deviation/average) $\mathrm{x}$ 100]. The accuracy data is calculated \% recovery using the formula [(measured concentration / known concentration) x 100]. Data on biological validation and sample collection times were analyzed using the T-test.

\section{Results and Discussion}

\subsection{ELISA Kit Validation}

Diluted fecal samples (1:10 to 1:160) showed a decrease in cortisol concentrations in line with increased levels of dilution (Table 1). Moreover, the serial dilutions of fecal samples (pre-and post-transportation) generated curves that were parallel to the cortisol standard curve (Figure 1, Table 1). The slopes of the pre-and post-transportation gave a value that was similar (not significantly different) to the slope of the cortisol standard curve $(p>0.05)$. The accuracy of EIA-K003-H5 kit was 99,76 $\pm 3.77 \%$. Intraassay (within microplate) coefficient of variation (\% CV) was $4.65 \%$, and $3.72 \%$ for Low-Quality Control (QC Low) and High-Quality Control (QC-high), respectively. Whereas \%CV of inter-assay (between microplate) was $0.94 \%$, and $4.48 \%$ for QC Low and QC high, respectively. The sensitivity of the EIA-K003-H5 kit was $27.6 \mathrm{pg} / \mathrm{mL}$, while the limit of detection was $45.5 \mathrm{pg} / \mathrm{mL}$. These results indicate that EIA-K003-H5 kit is an analytically reliable assay for measuring cortisol concentrations in feces of Aceh cows.

Table 1. Fecal cortisol concentrations after serial diluted and measured using EIA-K003-H5 kit.

\begin{tabular}{lll}
\hline \multirow{2}{*}{$\begin{array}{c}\text { Dilution } \\
\text { levels }\end{array}$} & \multicolumn{2}{c}{$\begin{array}{c}\text { The concentration of fecal cortisol } \\
\text { measured }(\mathrm{ng} / \mathrm{mL})\end{array}$} \\
\cline { 2 - 3 } & $\begin{array}{l}\text { Pre-transportation } \\
\text { sample }\end{array}$ & $\begin{array}{l}\text { Post- } \\
\text { transportation } \\
\text { sample }\end{array}$ \\
\hline $1: 10$ & 48.05 & 69.20 \\
$1: 20$ & 21.80 & 31.80 \\
$1: 40$ & 11.43 & 17.44 \\
$1: 80$ & 7.71 & 9.79 \\
$1: 160$ & 4.31 & 4.12 \\
\hline
\end{tabular}

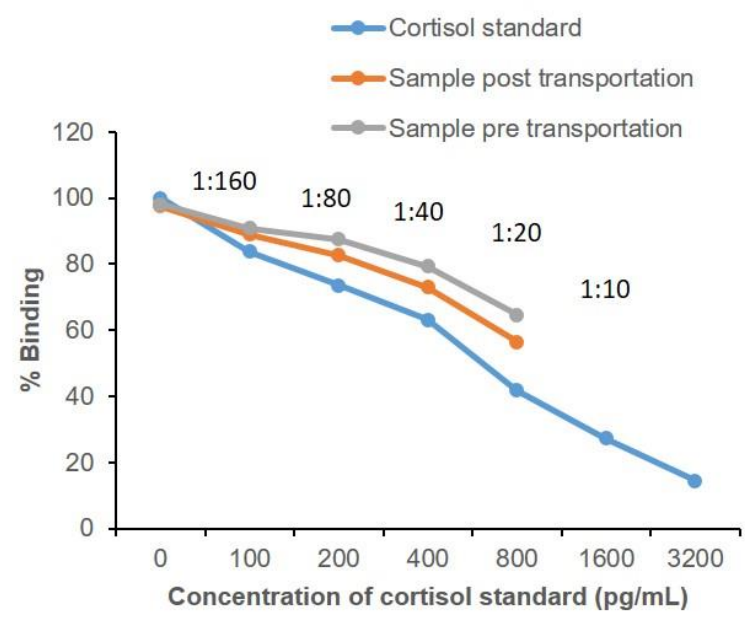

Figure 1. Curves of parallelism from cortisol standard and diluted samples of pre-transportation and post-transportation.

The mean \pm SD of the fecal cortisol concentrations before transportation (pre-transportation) and after transportation (post-transportation) was $80.09 \pm 36.95$ $\mathrm{ng} / \mathrm{mL}$, and $120.01 \pm 52.95 \mathrm{ng} / \mathrm{mL}$, respectively. The fecal cortisol concentrations post-transportation were significantly higher ( $33.27 \%)$ compared to pretransportation samples ( Figure 2). These results indicate that EIA-K003-H5 kit is a biologically reliable assay for measuring cortisol concentrations in feces of Aceh cows. This is because the biological validation showed a clear biological significance before and after transportation reflecting the physiological condition of the animals [5].

\subsection{Plasma Cortisol Concentrations of Aceh Cows}

Cortisol concentrations in plasma of Aceh cows collected in the morning and afternoon were presented in Table 2. 
The mean $( \pm \mathrm{SD})$ of plasma cortisol concentration in the morning and the afternoon was $39.24 \pm 24.43 \mathrm{ng} / \mathrm{ml}$ and $21.88 \pm 13.18 \mathrm{ng} / \mathrm{ml}$, respectively. Concentrations of cortisol concentration in plasma collected in the morning were significantly higher at $79.34 \%$ compared to the afternoon $(\mathrm{p}<0.05)$. This result indicates that cortisol concentrations in plasma of Aceh cows show a diurnal variation.

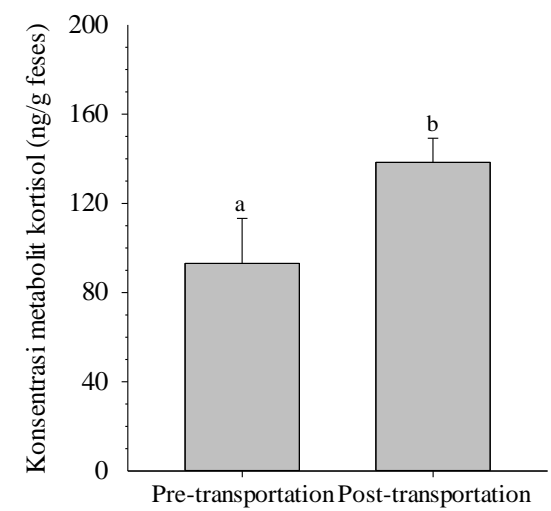

Figure 2. The mean \pm SD of fecal cortisol concentration before transportation (pre-transportation) and after transportation (posttransportation). Different superscripts above histogram indicate a significant difference between group $(\mathrm{p}<0.05)$

Table 2. Plasma cortisol concentrations of Aceh cows collected in the morning and afternoon.

\begin{tabular}{lll}
\hline \multirow{2}{*}{ Samples } & \multicolumn{2}{l}{ Sample collection time } \\
\cline { 2 - 3 } & Morning & Afternoon \\
\hline & - & \\
& -------- ng/ml ------ \\
1 & 19.15 & 16.98 \\
2 & 32.32 & 19.15 \\
3 & 13.77 & 2.75 \\
4 & 26.73 & 15.94 \\
5 & 22.88 & 11,11 \\
6 & 72.45 & 31.91 \\
7 & 76.38 & 40.57 \\
8 & 52.45 & 36.65 \\
\hline
\end{tabular}

\begin{tabular}{c}
\hline Mean \pm SD $\quad \mathbf{3 9 . 2 4} \pm \mathbf{2 4 . 4 3}{ }^{\text {a }} \quad \mathbf{2 1 . 8 8} \pm \mathbf{1 3 . 1 8}^{\text {b }}$ \\
\hline Note: ${ }^{\text {a,b }}$ Different superscripts showed significant differences \\
$(\mathrm{p}<0.05)$.
\end{tabular}

According to Cauter et al. [15], determine the diurnal variation of cortisol in plasma can be carried out in a basal condition, a condition when exogenous challenge can be controlled. It is important because the variation of cortisol secretion can be observed without the influence of external factors. For diurnal animals such as cattle, plasma cortisol concentrations will increase in the morning in response to the presence of a signal of stimulation from the body (endogenous stimulatory signal) which will eventually trigger the circadian pacemaker that is in the suprachiasmatic nuclei of the hypothalamus. Furthermore, the hypothalamus-pituitaryadrenal (HPA) axis will respond by releasing corticotropin-releasing hormone $(\mathrm{CRH})$ from the paraventricular nucleus from the hypothalamus to the anterior pituitary that will increase the release of an adrenocorticotropic-releasing hormone (ACTH) into the bloodstream. ACTH secretion will further trigger the adrenal cortex to release glucocorticoid hormones in the form of cortisol, corticosterone, or a combination of both [16]. In the afternoon and evening, plasma cortisol concentrations will decrease as a reflex of the recovery process from HPA to endogenous signals [15].

The results of this study were similar to the previous studies that have reported diurnal variation of cortisol concentrations in plasma such as in horses [11]. In dogs, it was reported that cortisol concentrations were high at 10.00 and $13.00(46.5 \pm 17.0 \mathrm{nmol} / \mathrm{L})$ and decreased to reach concentrations of $38.9 \pm 16.0 \mathrm{nmol} / \mathrm{L}$ at $19: 00$ and 22:00 [17]. However, in contrast to Aceh cattle, horses and dogs, cortisol concentrations in rats are also showing diurnal variations, but the highest concentrations can be seen at $20.00(13.98 \pm 0.54 \mathrm{ng} / \mathrm{ml})$ and the lowest concentrations in the morning at $8: 00(7.85 \pm 0.35 \mathrm{ng} / \mathrm{ml}$ [18]. This due to the rat is a nocturnal animal that active during the night, whereas Aceh's cattle, horses and dogs are diurnal animals that are active during the day.

The variation in cortisol concentrations in plasma of Aceh cow collected in the morning and afternoon indicates the importance of evaluating the time of collection of blood samples. This is because the differences in sample collection time will give a different result. Therefore, to monitor stress in Aceh cows through the measurement of cortisol from blood, the time of sample collection must be uniformed to avoid the effects of diurnal variation.

\subsection{Cortisol Concentration in Feces}

Different results were seen in the fecal cortisol concentrations. The concentration of fecal cortisol collected in the morning and afternoon was relatively similar (Table 3$)$. The mean $( \pm$ SD) of fecal cortisol concentration in the morning and afternoon was $50.91 \pm$ $15.27 \mathrm{ng} / \mathrm{g}$ feces, and $47.59 \pm 15.78 \mathrm{ng} / \mathrm{g}$ feces, respectively. The differences in cortisol concentrations in feces collected in the morning and afternoon were only about $6.98 \%$ and it was not significantly $(p>0.05)$. This result indicates that cortisol concentrations in feces of Aceh cow did not display a diurnal variation.

According to Heistermann et al. [19], diurnal variations often seen in blood or urine but less likely to occur in the fecal samples, especially in large animals. This is presumably because the measured hormones in the fecal are hormones that resulted from the metabolism which requires a long process until the time of the metabolites excreted in the feces. Therefore, hormone metabolites from feces are accumulations of metabolic products released in the feces [20].

According to Palme [21], after steroid hormones are produced by the endocrine glands and circulated through the blood circulation system, the hormones are metabolized and inactivated in target organs, liver, and 
kidneys which then released by the body through the digestive tract, urinary tract, salivary glands, and udder glands. This inactivation is needed to stop and control the activity of hormones in target organs and body physiology [22]. In fecal samples, steroid metabolites are excreted between 30 minutes to several days depending on the species, activity and even season [21]. However, on large mammals, the process generally ranged from one to two days [13].

Table 3. Fecal cortisol concentrations in Aceh cows collected in the morning and afternoon

\begin{tabular}{|c|c|c|}
\hline \multirow{2}{*}{ Samples } & \multicolumn{2}{|c|}{ Sample collection time } \\
\hline & Morning & Afternoon \\
\hline & \multicolumn{2}{|c|}{--------- ng / g feces ------ } \\
\hline 1 & 55.28 & 42,611 \\
\hline 2 & 56.21 & 21.72 \\
\hline 3 & 41.09 & 40.64 \\
\hline 4 & 68.08 & 71.82 \\
\hline 5 & 27.28 & 38.62 \\
\hline 6 & 33.07 & 44.97 \\
\hline 7 & 66.25 & 58.1 \\
\hline 8 & 60.03 & 62.28 \\
\hline Mean \pm SD & $50.91 \pm 15.27^{\mathrm{a}}$ & $47.59 \pm 15.78^{a}$ \\
\hline
\end{tabular}

The results are consistent with the previous studies in other large animals such as the gorilla, Gorilla gorilla gorilla [13], orangutan, Pongo sp. [23], Rhino, Diceros bicornis [24], baboons, Papio Cynocephalus cynocephalus [25] . However, in fecal samples, diurnal variation of the fecal cortisol is often seen in the small animals e.g., in marmoset monkeys, Callithrix jacchus [26], snow rabbits, Lepus americanus [27], mice [28], and spider monkeys, Ateles hybridus [12]. This is because the time required to metabolize the hormones in small animals are generally shorter [29].

Considering the time of the fecal sample collection did not affect the concentration of fecal cortisol in Aceh cow, the sampling time of fecal samples to monitor stress hormones can be conducted in the morning, afternoon or throughout the day. This is an advantage and a practical value for researchers in the field when using fecal samples for the analysis of the cortisol.

\section{Conclusion}

A commercial cortisol ELISA kit(EIA-K003-H5) is a reliable assay to be used for measuring cortisol concentrations in feces of Aceh cow. There is a diurnal variation of the plasma cortisol concentration in which plasma cortisol concentrations were higher in the afternoon than in the afternoon. But, fecal cortisol concentrations did not.

\section{Acknowledgments}

We would like to thanks to the Ministry of Research, Technology and Higher Education, Indonesia for funding this research project [Grant No. 215/SP2H/LT/DPRM/2019].

\section{References}

1. IPCC (Intergovernmental Panel on Climate Change). Climate Change: Synthesis Report; Summary for Policymakers. 2014. Available from: https://www.ipcc. ch/pdf/assessmentreport/ar5/syr/AR5_SYR_FINAL_SPM .pdf. Last accessed on 25-08-2018.

2. Bova TL, Chiavaccini L, Cline GF et al:: Environmental stressors influencing hormones and systems physiology in cattle. Reproductive Biology and Endocrinology, 2014, 12:58

3. Upadhyay RC, Rita Rani A, Singh SV et al.: Impact of climate change on reproductive functions of Murrah buffaloes. J. Anim. Plant Sci., 2012, 22(3): 234-236.

4. Das GK, Khan FA. Summer anoestrus in buffalo- $A$ review. Reprod. Domest. Anim. 2010, 45: e483-e494.

5. Gholib G, Wahyuni S, Akmal M, et al.: The validation of a commercial enzyme-linked immunosorbent assay and the effect of freeze-thaw cycles of serum on the stability of cortisol and testosterone concentrations in Aceh cattle [version 1; peer review: 1 approved, 1 approved with reservations]. F1000Research 2019, 8:1220.

6. Sheriff MJ, Dantzer B, Delehanty B et al. : Measuring stress in wildlife: techniques for quantifying glucocorticoids. Oecologia, 2011, 166(4):869-887.

7. Gholib G, Heistermann M, Agil M, et al. : Comparison of fecal preservation and extraction methods for steroid hormone metabolite analysis in wild crested macaques. Primates, 2018, 59 (3):1-12.

8. Nugraha TP, Heistermann M, Agil M, et al.: Validation of a field-friendly extraction and storage method to monitor fecal steroid metabolites in wild orangutans. Primates 58, 2017, (2): 285-294

9. Turriani M, Bernabo N, Barboni B, et al.: Circadian rhythm and stress response in droppings of serinus canaria. Veterinary Medicine International. 2016

10. Gholib G, Wahyuni S, Kadar OH, et al.: Measurement of serum testosterone in kacang goat by using enzymelinked immunosorbent assay (ELISA) technique: the importance of kit validation. Jurnal Kedokteran Hewan. 2016. 10(1):32-36.

11. Pawluski J, Jego P, Henry S, et al. : Low plasma cortisol and fecal cortisol metabolite measures as indicators of compromised welfare in domestic horses (Equus caballus). Journal Pone. 2017. 10(137):1-18.

12. Rimbach R, Heymann EW, Link A, et al. : Validation of an enzyme immunoassay for assessing adrenocortical activity and evaluation of factors that affect levels of fecal glucocorticoid metabolites in two New World primates. General and Comparative Endocrinology. 2013. 191:13-23. 
13. Shut K, Setchell JM, Heistermann M. Non-invasive monitoring of physiological stress in the Western lowland gorilla (Gorilla gorilla gorilla) : Validation of a fecal glucocorticoid assay and methods for practical application in field. General and Comparative Endocrinology. 2012. 179:167-177.

14. Zar JH: Biostatistical Analysis. Prentice Hall, Upper Saddle River, N.J.1996.

15. Cauter EV, Leproult R, Kupfer DJ : Effects of gender and age on the levels and circadian rhytmicity of plasma cortisol. Journal of Clinical Endocrinology and Metabolism. 1996.7:2468-2473.

16. Reeder $M$, Kramer $K M$ : Stress in free-ranging mammals: integrating physiology, ecology, and natural history. Journal of Mammalogy. 2005. 86(2):225-235.

17. Kolevska J, Brunclik V, Svoboda M : Circadian rhythm of cortisol secretion in dogs of different daily activities. Acta Veterinaria. 2003. 72:599-605.

18. Gong S, Miao YL, Jiao GZ, et al.: Dynamics and correlation of serum cortisol and corticosterone under different physiological or stressful conditions in mice. PLoS ONE. 2015. 10(137):3-14.

19. Heistermann M, Palme R, Ganswindt A : Comparison of different enzyme-immunoassay for assessment of adrenocortical activity in primates based on fecal analysis. American Journal of Primatology. 2006. 273:257-273.

20. Hirschenhauser K, Kotrschal K, Möstl E : Synthesis of measuringsteroid metabolites in goose feces. Annals of the New York Academy of Sciences. 2005. 1046 (1):138153.

21. Palme R: Measuring fecal steroids: Guidelines for practical application. Annals of the New York Academy of Sciences. 2005. 1046(1):75-80.
22. Möstl E, Rettenbacher S, Palme R: Measurement of corticosterone metabolites in birds' droppings: An analytical approach. Annals of the New York Academy of Sciences. 2005. 1046(1) : 17-34.

23. Weingrill T, Willems EP, Zimmermann N, et al. : Speciesspecific pattern in fecal glucocorticoid and androgen levels in zoo living orangutans (Pongo spp). General and Comparative Endocrinology. 2011. 172:446-457.

24. Schwarzenberger F, Möstl E, Palme R, et al.: Faecal steroid analysis for non-invasive monitoring of reproductive status in farm, wild and zoo animals. Animal Reproduction Science. 1996. 42:515-526.

25. Wasser SK, Thomas R, Nair PP, et al. : Effects of dietary fibre on fecal steroid measurement in baboons (Papio cynocephalus cynocephalus). Journal of Reproduction and Fertility. 1993. 97:569-574.

26. Sousa MBC, Ziegler TE. Diurnal variation on the excretion patterns of fecal steroids in common marmoset (Callithrix jacchus) females. American Journal of Primatology. 1998. 46:105-117.

27. Sheriff MJ, Bosson CO, Krebs CJ, et al. : A non-invasive technique for analyzing fecal cortisol metabolites in snowshoe hares (Lepus americanus). Journal of Comparative Physiology. 2009. 179:305-313.

28. Kalliokoski O, Jacobsen KR, Teilmann AC, et al. Quantitative effects of diet on fecal corticosterone metabolites in two strains of laboratory mice. In Vivo. 2012. 26:213-221.

29. Touma C, Sachser N, Möstl E, Palme R. Effects of sex and time of day on metabolism and excretion of corticosterone in urine and feces of mice. General and Comparative Endocrinologi. 2003. 130:267-278. 